\title{
102. Intracrystalline Exchange Equilibrium in Silicate Solid Solutions
}

\author{
Yoshito Matsui and Shohei Banno \\ (Comm. by Seitarô Tsubor, M.J.A., June 12, 1965)
}

Introduction. The exchange equilibrium between silicate solid solutions has been studied by many authors, including Ramberg and De Vore (1951), Kretz (1961), Bartholomé (1962), Mueller (1961, 1962 $a, b)$, and Craig (1964). It has been clarified that many ferromagnesian minerals behave as ideal solutions, but a notable exception was found by Mueller (1961a) in the pair actinolite-cummingtonite. Later Mueller $(1962 \mathrm{a}, \mathrm{b})$ derived an equilibrium relation of $\mathrm{Mg}$ and $\mathrm{Fe}$ between the sublattices within cummingtonite, which explains the observed distribution of them (Ghose, 1962). This is based on the assumption that crystallographic sites with the same geometry in different minerals are energetically equivalent, the assumption to be referred to as Mueller's postulate.

In this paper, the exchange equilibrium among three energetically non-equivalent sites, two in one mineral and one in another, is treated. The relevant exchange reactions are assumed strictly ideal. This model may have been suggested by Mueller (1962 a,b) in implicit manner. Nevertherless explicit presentation of the model results in very useful equations, which enable us to obtain the intracrystalline equilibrium constant without invoking Mueller's postulate. They also give us a clear picture of the apparent non-ideal behavior in the exchange equilibria, without dealing with the regular solution model, leading in turn to the prediction of the existence of non-ideal behavior not yet detected.

Theory of the binary solid solutions. Let us consider a pair of binary solid solutions, (X, Y) $A$ and $(\mathrm{X}, \mathrm{Y}) B$, where the lattice sites in A are of two kinds, energetically distinguished from each other, and those in $\mathrm{B}$ are of one kind, all energetically equivalent. We assume that the ion exchange reactions can be expressed by the chemical equations:

$$
\begin{aligned}
& \mathrm{X}_{1}^{\mathrm{A}}+\mathrm{Y}^{\mathrm{B}}=\mathrm{Y}_{1}^{\mathrm{A}}+\mathrm{X}^{\mathrm{B}}, \\
& \mathrm{X}_{2}^{\mathrm{A}}+\mathrm{Y}^{\mathrm{B}}=\mathrm{Y}_{2}^{\mathrm{A}}+\mathrm{X}^{\mathrm{B}}, \\
& \mathrm{X}_{1}^{\mathrm{A}}+\mathrm{Y}_{2}^{\mathrm{A}}=\mathrm{Y}_{1}^{\mathrm{A}}+\mathrm{X}_{2}^{\mathrm{A}},
\end{aligned}
$$

where $\mathrm{X}_{1}^{\mathrm{A}}$ denotes the ion $\mathrm{X}$ in the site 1 of $\mathrm{A}$, etc. In the case of ideal solid solutions, the mass action law can be expressed by the following equations : 


$$
\begin{aligned}
\frac{X_{1}^{\mathrm{A}}}{1-X_{1}^{\mathrm{A}}} & =K_{1} \frac{X^{\mathrm{B}}}{1-X^{\mathrm{B}}}, \\
\frac{X_{2}^{\mathrm{A}}}{1-X_{2}^{\mathrm{A}}} & =K_{2} \frac{X^{\mathrm{B}}}{1-X^{\mathrm{B}}},
\end{aligned}
$$

and

$$
\frac{X_{1}^{\mathrm{A}}}{1-X_{1}^{\mathrm{A}}}=K_{i} \frac{X_{2}^{\mathrm{A}}}{1-X_{2}^{\mathrm{A}}} ; K_{i}=\frac{K_{1}}{K_{2}}
$$

where $X_{1}^{\Lambda}$ means the atomic fraction of $\mathrm{X}$ in the site 1 of $\mathrm{A}$, etc. When the ratio of the numbers of the sites 1 and 2 in $\mathrm{A}$ is $m: n$ $(m+n=1)$, the overall atomic fractions $X^{\Lambda}$ and $Y^{A}\left(=1-X^{A}\right)$ are given by the following equation:

$$
X^{\mathrm{A}}=m X_{1}^{\mathrm{A}}+n X_{2}^{\mathrm{A}} .
$$

Combination of Eqs. (1), (2), and (4) leads to the equation:

$$
\begin{gathered}
\frac{X^{\mathrm{A}}}{1-X^{\mathrm{A}}}=K^{\prime} \frac{X^{\mathrm{B}}}{1-X^{\mathrm{B}}} ; \\
K^{\prime}=\frac{\left(K_{1} K_{2}-m K_{1}-n K_{2}\right) X^{\mathrm{B}}+m K_{1}+n K_{2}}{\left(n K_{1}+m K_{2}-1\right) X^{\mathrm{B}}+1} .
\end{gathered}
$$

Obviously $K^{\prime}$ is not constant, but is dependent on $X^{\mathrm{B}}$, except in the special case where $K_{1}=K_{2}$. This implies that this system can no longer be considered ideal in the exchange reaction.

The direct determination of $X_{1}^{\mathrm{A}}$ or $X_{2}^{\mathrm{A}}$ is troublesome, and it is desirable to find some way to estimate the constants such as $K_{1}$ and $K_{2}$ from some easily observable quantities, e.g., $X^{\mathrm{A}}$ and $X^{\mathrm{B}}$.

In some cases the extrapolation technique may be useful, since

$$
\lim _{x^{\mathrm{B}} \rightarrow 0} K^{\prime}=m K_{1}+n K_{2}
$$

and

$$
\lim _{x^{\mathrm{B}} \rightarrow 1} K^{\prime}=\frac{K_{1} K_{2}}{n K_{1}+m K_{2}} \text {. }
$$

If $\lim _{x^{\mathrm{B}} \rightarrow 0} K^{\prime}$ and $\lim _{x^{\mathrm{B} \rightarrow 1}} K^{\prime}$ can be estimated with sufficient accuracy, $K_{1}$ and $K_{2}$ (and hence $K_{i}$ ) may be obtainable by the simultaneous solution of Eqs. (6) and (7). However, for the estimation of $K_{1}$ and $K_{2}$, it appears more convenient to carry out the least squares calculation using the observed $X^{\mathrm{B}}$ and $K^{\prime}$ data.

Here it is felt necessary to mention that in our model the overall activity of $X$ in the mineral $\mathrm{A}\left(a_{\mathrm{X}}^{\mathrm{A}}\right)$ is given as

$$
a_{\mathrm{X}}^{\mathrm{A}}=\left(X_{1}^{\mathrm{A}}\right)^{m} \cdot\left(X_{2}^{\mathrm{A}}\right)^{n} \text {, }
$$

since the chemical potentials of $X\left(\mu_{\mathrm{X}}\right)$ in each site can be expressed as

and

$$
\begin{aligned}
& \mu_{\mathrm{X}_{1}}=\mu_{\mathrm{x}_{1}}^{0}+\mathrm{RT} \ln X_{1}^{\mathrm{A}} \\
& \mu_{\mathrm{X}_{2}}=\mu_{\mathrm{X}_{2}}^{0}+\mathrm{RT} \ln X_{2}^{\mathrm{A}},
\end{aligned}
$$

where $\mu_{\mathrm{x} 1}$ denotes the $\mu_{\mathrm{x}}$ for the site 1 of mineral $A$, etc. Therefore the overall chemical potential of $\mathrm{X}$ in $\mathrm{A}$ is given by

$$
\mu_{\mathrm{x}}^{\mathrm{A}}=m \mu_{\mathrm{x} 1}+n \mu_{\mathrm{x} 2} \text {. }
$$


This expression of $\mu_{x}^{\mathrm{A}}$ is equivalent to what Mueller $(1962 \mathrm{a}, \mathrm{b})$ considered to be "simplified approximation", which however, is by no means an approximation.

Apparent non-ideal behavior in the pair actinolite-cummingtonite. The most remarkable deviation from the ideal behavior has been found in the exchange equilibrium of $\mathrm{Mg}$ and $\mathrm{Fe}$ (II) between actinolite and cummingtonite in an extensive investigation by Mueller (1961). As demonstrated by him (Mueller, $1962 \mathrm{a}, \mathrm{b}$ ), cummingtonite is a mineral of type $\mathrm{A}$ which has two energetically non-equivalent sites, whereas actinolite is that of type $B$.

In this case, Eqs. (1), (2) etc. can be written as follows:

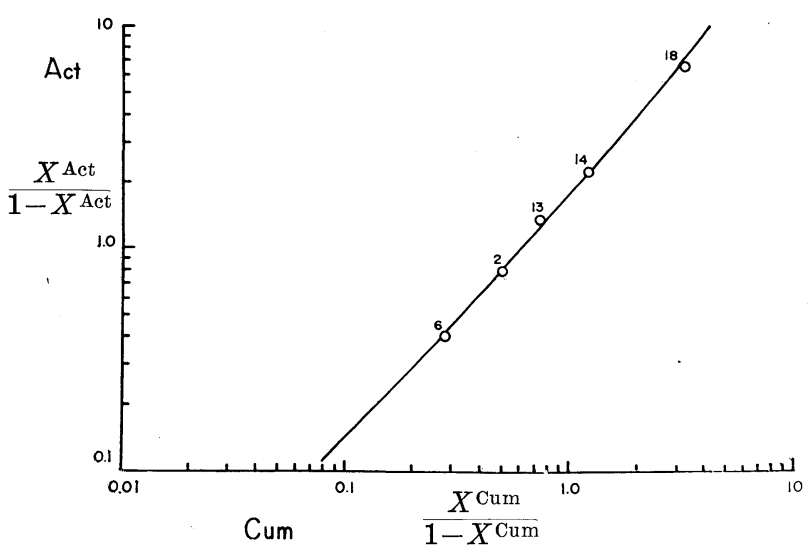

$$
\begin{aligned}
& \frac{X_{V}^{\text {Cum }}}{1-X_{V}^{\text {Cum }}}=K_{1} \frac{X^{\text {Act }}}{1-X^{\text {Act }}}, \\
& \frac{X_{W}^{\text {Cum }}}{1-X_{W}^{\text {Cum }}}=K_{2} \frac{X^{\text {Act }}}{1-X^{\text {Act }}}, \quad \text { etc. },
\end{aligned}
$$

where $X_{V}^{\text {cum }}$ denotes the atomic fraction of $\mathrm{Mg}$ in the sublattice $V^{*}$ ) of cummingtonite, etc. Since the ratio of numbers of sublattice points $V$ and $W$ in cummingtonite is $2: 5$, we have from Eq. (5):

$$
K^{\prime}=\frac{X^{\mathrm{Cum}} /\left(1-X^{\mathrm{Cum}}\right)}{X^{\text {Act }} /\left(1-X^{\text {Act }}\right)}=\frac{\left(7 K_{1} K_{2}-2 K_{1}-5 K_{2}\right) X^{\text {Act }}+2 K_{1}+5 K_{2}}{\left(5 K_{1}+2 K_{2}-7\right) X^{\text {Act }}+7} .
$$

Using the data by Mueller (1961) we can estimate the two constants, $K_{1}$ and $K_{2}$, by the application of the method of least squares to Eq. $\left(5^{\prime}\right)$, so that the observed $K^{\prime}$ values are best approximated by Eq. $\left(5^{\prime}\right)$. Thus we find

$$
K_{1}=0.121, \quad K_{2}=0.946, \quad K_{i}=0.128 \text {. }
$$

*) Notation by Mueller (1962 a) is used in this paper. $W$ corresponds to $M_{1}$. $M_{2}$, and $M_{3}$ in the customary crystallographic notation, and $V$ to $M_{4}$. 
Placing these parameters into Eq. $\left(5^{\prime}\right)$, we can reproduce the relation between $X^{\mathrm{cum}} /\left(1-X^{\mathrm{cum}}\right)$ and $X^{\text {Act }} /\left(1-X^{\text {Act }}\right)$ as is shown in Fig. 1. Obviously the calculated curve matches the observed points quite satisfactorily. It should be noted also that the estimated value of $K_{2}$ is very close to unity, in harmony with the Mueller's postulate.

From the above considerations it appears that the non-ideal behavior of cummingtonite originates from the fact that this mineral has two sublattices of distinctly different characters.

Possible non-ideal behavior in the pair clinopyroxene and orthopyroxene. If the generalization deduced just above is reasonable, there should also exist some deviation from ideal mixture in the exchange equilibrium of $\mathrm{Mg}$ and $\mathrm{Fe}(\mathrm{II})$ between orthopyroxene, which is a mineral of type A, and clinopyroxene, which is of type B. However, no significant deviation has been detected as yet (Mueller, $1962 \mathrm{a}, \mathrm{b}$ ).

In this case the following equations may hold:

and

$$
\begin{gathered}
\frac{X_{1}^{\mathrm{opx}}}{1-X_{1}^{\mathrm{opx}}}=K_{1} \frac{X^{\mathrm{ppx}}}{1-X^{\mathrm{cpx}}}, \\
\frac{X_{2}^{\mathrm{opx}}}{1-X_{2}^{\mathrm{opx}}}=K_{2} \frac{X^{\mathrm{cpx}}}{1-X^{\mathrm{ppx}}},
\end{gathered}
$$

where $X$ denotes the atomic fraction of $\mathrm{Mg}$, and the superscripts Opx and Cpx refer to ortho- and clinopyroxenes, respectively. Subscript 1 refers to the sublattice position in orthopyroxene which corresponds the Ca position in clinopyroxene. Since the ratio of the numbers of sublattice points 1 and 2 is $1: 1$ in orthopyroxene, Eq. (5) can be written as

$$
K^{\prime}=\frac{X^{\mathrm{opx}} /\left(1-X^{\mathrm{opx}}\right)}{X^{\mathrm{cpx}} /\left(1-X^{\mathrm{cpx}}\right)}=\frac{\left(2 K_{1} K_{2}-K_{1}-K_{2}\right) X^{\mathrm{cpx}}+K_{1}+K_{2}}{\left(K_{1}+K_{2}-2\right) X^{\mathrm{cpx}}+2} .
$$

The estimation of $K_{1}$ and $K_{2}$ may be possible, in principle, by the same procedure as used in the preceding section. However, as is seen in Fig. 2, the observed points are so scattered that the application of the least squares calculation is hardly justifiable. Therefore it is convenient to invoke the Mueller postulate, which requires, in this case, that $K_{2}$ should be unity (Mueller, $1962 \mathrm{a}, \mathrm{b}$ ).

Based on the data compiled by Mueller (1961), we assume now that $K^{\prime}=0.549$ when $X^{\mathrm{cpx}}=2 / 3$ (cf. Fig. 2). Substituting these values together with $K_{2}=1$ into Eq. $\left(5^{\prime \prime}\right)$, we have tentative value of $K_{1}$ which equals 0.302 . Use of these constants in Eq. (5") results in a possible relation between $X^{\mathrm{opx}} /\left(1-X^{\mathrm{opx}}\right)$ and $X^{\mathrm{cpx}} /\left(1-X^{\mathrm{cpx}}\right)$ as shown graphically in Fig. 3.

Here it is important to note that the expected deviation from ideal mixture is so small that it is almost impossible to decide from 


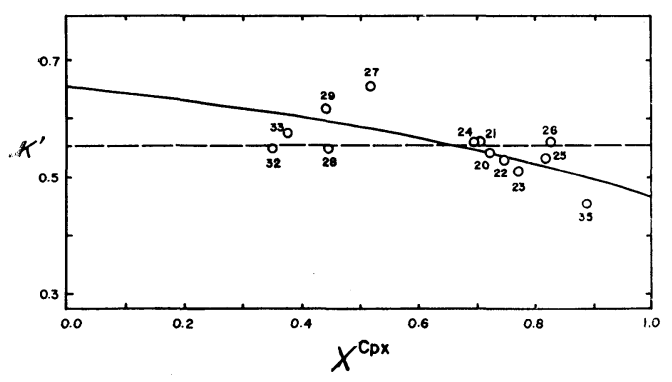

Fig. 2. Plots of the apparent distribution coefficients $\left(K^{\prime}\right)$ of $\mathrm{Mg}$ and $\mathrm{Fe}$ (II) between orthoand clinopyroxenes versus the atomic fractions of $\mathrm{Mg}$ in clinopyroxene. Data are all taken from the compilation by Mueller (1961). Solid line: Theoretical relation based on Eq. (5 $\left.5^{\prime \prime}\right)$ with $K_{1}=0.302$ and $K_{2}=1.000$. Broken line: Simple ideal solution model with $K^{\prime}=0.533$.

the present data whether the exchange equilibrium is strictly ideal (i.e., $K^{\prime}$ is constant) or whether it deviates as indicated by Eq. ( $\left.5^{\prime \prime}\right)$. Evidently, in deciding the nature of the equilibrium, more rigorous discrimination is necessary so as to determine the physical conditions which were prevailing when the exchange reaction took place. Nevertheless, at present it can be said that the possible existence of nonideal behavior in this reaction can never be ruled out, so that our model of apparent non-ideal mixture is still plausible.

Concluding remarks. In the preceding discussion it is demonstrated that the slight departure from ideal solution in the silicate solid solutions can be explained in terms of the ideal exchange equilibria among several energetically (or crystallographically) different sublattices with reasonable success. At present it must be emphasized that there appears to be no reason to introduce any more sophisticated models. It is felt far more important to provide more accurate and physically meaningful analyses than to devise such models.

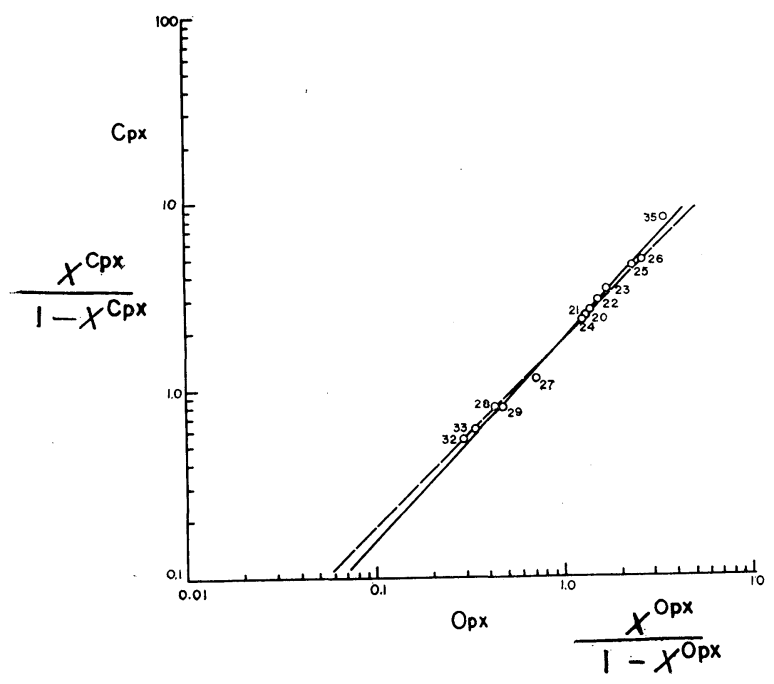

Fig. 3. Distribution of $\mathrm{Mg}$ and $\mathrm{Fe}(\mathrm{II})$ between orthoand clinopyroxenes. Solid line: Intracrystalline equilibrium model. Broken line: Simple ideal solution model. See caption of Fig. 2. 
As is shown in the example of ortho- and clinopyroxenes, the: effect of the intracrystalline equilibrium is expected to be relatively small in most cases, and hence we may speak of the exchange equilibria as nearly ideal except in some special cases. In the pair of minerals which both having sublattices, for example olivine and orthopyroxene, the effect of the intracrystalline equilibrium may be such that the apparent deviation becomes even smaller, because the deviations in both minerals may be similar and hence may cancel each other.

The present model can readily be extended to the ternary system in which the third element is a minor component. This problem will be discussed elsewhere.

Acknowledgements. We wish to express our sincere thanks to Prof. S. Umemoto and Dr. T. Iijima for their instructive suggestions, and to Mr. G. D. Stice for improving English expressions.

\section{References}

Bartholomé, P. (1962): Petrologic Studies (Buddington Volume, A. E. J. Engel et al., Eds.). pp. 1-20.

Craig, H. (1964): Isotopic and Cosmic Chemistry (Urey Volume, H. Craig et al... Eds.). North-Holland Publishing Co., pp. 401-451.

Ghose, S. (1962): Am. Mineralogist, 47, 388-394.

Kretz, R. (1961): J. Geol., 69, 361-387.

Mueller, R. F. (1961): Geochim. Cosmochim. Acta, 25, 267-296.

- (1962a): Geochim. Cosmochim. Acta, 26, 581-598.

- (1962b): Science, 137, 540-541.

Ramberg, H., and DeVore, G. (1951): J. Geol., 59, 193-210. 